\title{
The Effect of Spirituality Aspect in Workplace on Organizational Health (Survey on Social Security in Sistan and Baluchestan)
}

\author{
Farangis Shahraki Ebrahimi* \\ Department of Management, college of human sciences, Islamic Azad University, Kerman, Iran \\ ${ }^{*}$ Corresponding Author Email: Shahraki1369@gmail.com
}

\section{Dr. Mehdi Kazemi}

Assistant Professor in Management, University of Sistan and Baluchestan, Zahedan, Iran Email: Mehdykazami@gmail.com

\section{Dr. Sanjar Salajegheh}

Assistant Professor in Management, college of human sciences, Islamic Azad University, Kerman, Iran Email: salajeghe-187@yahoo.com

Doi:10.5901/mjss.2016.v7n3s3p239

\begin{abstract}
Life is meaningless without a job, but work without the soul is life destroyed. Spirituality at work is one of the new topics in the discussions was organizational. The aim of this study was to evaluate the effect dimensions of spirituality in the workplace on Organization health of security organization the statically population of Sistan and Baluchestan. Current employees of the social security organization Sistan and Baluchestan province, which is based on Morgan 225 subjects were chosen and data SPSS software and multiple liner regressions analysis was investigated. The results showed that the in three dimensions (work with meaning, sense of solidarity and alignment values) as a spiritual in workplace that can impact on organizational health transition is by no means the organizational health. No significant work on organizational health been effective and that the proposed model for others aspects of spirituality in Iran Will be effective.
\end{abstract}

Keywords: Spirituality of workplace, Organization health

\section{Introduction}

Spirituality in the workplace is one of the important business processes and labor and management in twenty-first century is since the mid-nineties seriously raised, Because of the interest in spirituality environment business, increase organizational effectiveness. Encouragement spirituality in workplace can lead to benefits. Be great. One of the areas which management could have used lot spirituality, organizational change management. Which aim to help change the behavior of individuals in the organization and thus earn performance objectives effectively and fast? (Mohammadi et al: 2013).

The concept of positive organizational health in an organization, attention to a situation that developed the organization facilitates, or cause dynamics. Based on work by Parsonz, Bales and Sils(1953), hui and tarter(1997) and hovy Miskel (1991) organization S ability to adapt their environment, creating harmony among members and the achievement of corporate objectives, including benefits to as the use of organizational health. In fact the health physically, mentally, security, belong, merit and value to knowledge, expertise, character, and growth of potential beneficiaries they perform task assigned by the ultra-their impact on the effectiveness of any system the only force strong (Hosseini nasab, 2012). Spirituality and spiritual health is aim that physical, psychological and social human from (Khorasani et al, 2012). social anxiety this negative action will be stressed numerous studies have proven that the spirituality and spiritual health level increases the social health is also increasing a door the role of spirituality on health and social cohesion social control, reduce abnormal behaviors and deviation, a common key system and reform and deviant society, establishing a common intellectual and reform society and to change unhealthy thoughts noted, so that thoughts change unhealthy it can be noted, so that spirituality and spiritual health can have even toward perfection and excellence resulting in health mental and physical and social health eventually lead there gating stating the dimensions of spirituality workplace with 
meaning sense of solidarity and alignments values and organizational change leadership change the organizational climate and organizational learning capital attitudes and work together their workplace spirituality and organizational performance that the growing appeal of spirituality(Riahi et al., 2008, Gatling ,2015, Ajala,2013). In the workplace to develop new paradigm in science leading organization is. Spirituality workplace on employee happiness in an industrial setting is effective in this study will try to form a conceptual model of spirituality in workplace factors work on health socials security organization sistan and baluchestan be examined.

\section{Research Literature}

\subsection{The concept of spirituality}

Spirituality as a force energy, motivation, inspiration, spirit and life the constant search for meaning purpose destiny particular, many researchers, and spirituality considered as a source of stability for the organization which can realize the performance and the effectiveness of Divine help for different people depending on their attitude or worldview has several meanings. Here the spiritual life, necessarily belong to one of the established religions historically, it means having an attitude to the world and people to people peace, happiness and hope (Myers 1995, Mitroff and Denton 1999, Hannells 1995, Abedi Jafari and rastwgar, 2007, Myers 1990, Kavanagh 1999). The literature of spirituality in three is distinct ways: personal circumstances aspects themes of spirituality, and the characteristics spiritual.

\subsection{Concept of spirituality in the workplace}

It seems today's people wherever work; search something beyond rewards material in their work. They search something with meaning and hope and willful their balance spirituality (Gibbons 2001). The study of spirituality is nascent phenomenon in the workplace that can the powerful force of life positive; Because they help people to integrate and seamlessly the work and spiritual life, may almost they say a hundred thousand hour of work life and to improve and work more enjoyable, more balanced and make them more meaningful and educate their souls (Mitroff and Denton, 2003: 163). Spirituality in the work includes the conceptual a sense of integrity and continuity in the work and appreciation deep in work (Gibbons 2001). Also Hensen (2008) point out that the staff needs in terms of type and volume has changed and that today's organizations if they fail fully to biological needs, psychological, social and spiritual staff are accountable. Some researchers meet the new paradigm future challenges managing their spirituality they believe that satisfy the needs of high staff can be reached on issues search the dimensions of organizational spirituality (Kennedy, 2002). In term of their intensity can lead to make fun of employees.so for enjoy working in organizations is suggested that efforts further improve the spirituality in the workplace both at the individual level given that this component organizational spirituality is possible.

\subsection{Role of spirituality in organizational health}

By the time we live in: despite all improvements and facilities, dissatisfaction with life as a problem for all families and communities it is obvious. each day the number of people who believe spirituality factor affecting the quality of life and affliction and distress of their treatment and the experts in the treatments of diseases and maintain health focus on spiritual beliefs and behaviors, it will beaded(Riahi et al., 2008). several studies have shown that whatever spirituality and spiritual health increases. In the role of spirituality in health social cohesion and social control, reduction abnormal and deviant behavior, creating a system shared key and correct the disturbed society created a system of joint intellectual and social reform and change unhealthy thoughts can be cited, as it can be noted that the change unhealthy thought, so that spirituality and enjoyment of health can lead to a spiritual perfection and excellence resulting in physical and mental health and social conduct(Tahmasebi pour 2002). One force targeted the physical, social and psychological human form. Social anxiety can be negative action the tension. william james faith know the effective treatment for anxiety with it(Khorasani et al, 2012).It considers life to help people on according to studies religious beliefs in the prevention of depression and mental illness. Effective and the lack of such beliefs cause depressions. Ethno religious beliefs makes that people are less prone to stress be depressed and Gordon all port was the result of emotions not only rational religious nature and not an entirely irrational, but rather a fusion of feeling and thinking logical (Miliman, 2003). In fact, religion, philosophy of life for the person providing that only nature intellectually, but also satisfying for emotionally and emotional. So, all port result is that all the great religions of the world bring the followers kind of worldview that is simply not logical and harmonic beauty. In their study concluded that spirituality in the workplace, the causes job attitudes, 
organizational commitment, job involvement reduce, Intentions of leaving the service and more (Miliman, 2003). Therefore on spirituality in the workplace indirectly the attitude of the staff on citizenship organizational impact. State that the level wisdom spirituality in the workplace can contribute social and political sense of ties to member's organizations.

Hansson (2008) showed that organizational health through the freedom to make decisions and feel work affecting organizational health and positive impact. Lack of organizational health through discrimination, work stress communication and destructive practices on mental health had a negative effect. Nidhammer(2008) Came to conclusion that the lack of freedom in decision making, lack of job security and lack of social support on health staff psychological negative effects. Ajla(2013) This the researcher revealed that each of the three dimensions spirituality in the workplace(is meaningful, purpose full work and the sense of commitment and solidarity) specifically a positive impact on happiness employees. Moghimi (2007) in "the relationship between spirituality psychology and empowerment in the workplace organizational commitment" results positive relationship between workplace spirituality and organizational commitment and improvement. Gatling (2015) Task force showed a significant relationship between improves the effectiveness, sustainability, and normative commitments people showed. In his research work found that the growth of charm spirituality in the workplace to development paradigms new organizational science led. Topics in the workplace. Work to increase organizational performance and impact this is positive process. And the researcher in the process Spirituality framework for the effective work of performance is drawn. Gatling (2015) research found that the dimensions of spirituality in the workplace (work with meaning, sense of solidarity and sympathy value) and organizational change (change leadership, barley organizational capital and organizational learning) and attitudes working together there. And spirituality work environment and an opportunity that organizations performance to improve their effectiveness. Various research shows that organizational health variables such as effectiveness and cooperation between people, innovation, stress levels, progress and success, efficiency, improvement, education, decision making, organizational commitment there.

According to above two variables spirituality workplace and organizational health, to study and research is selected. Up to now this variable separately, as well as other factors affecting them have been investigated, but the relationship between spirituality in the workplace and there is little organizational health research is.

In this study is to spirituality workplace as factors that pose less it is to be further investigated by the consideration of organizational health as a factor. The conceptual model for workplace spirituality the first to be studied.

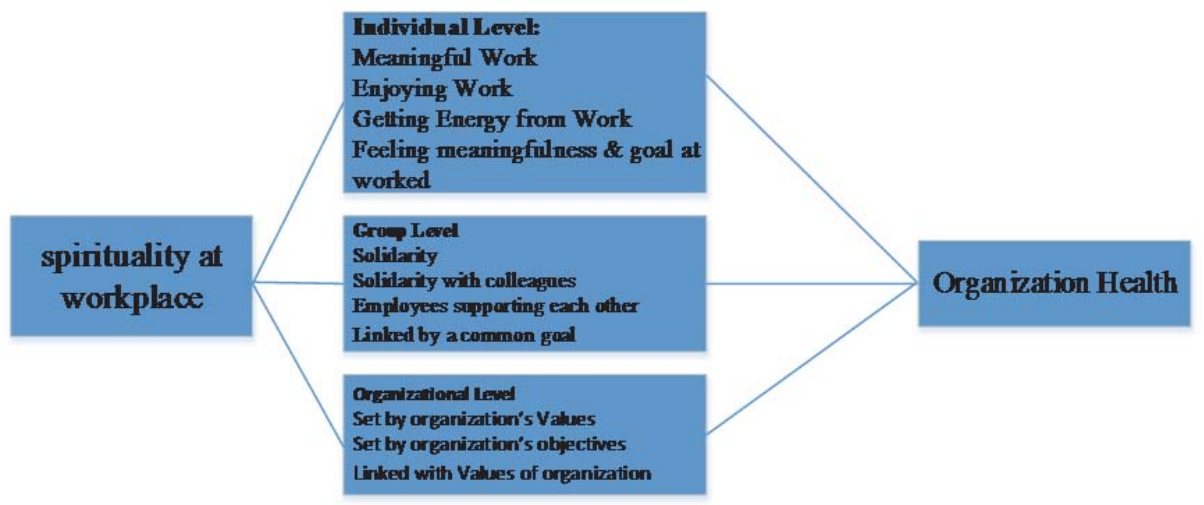

Figure1. Conceptual Model of Research

- Hypothesis 1: spirituality at work in the creation of health social security organization of sistan and baluchestan is effective.

- Hypothesis 2: the meaning of work in creating health social security organization of sistan and baluchestan is effective.

- Hypothesis 3: solidarity within the organization creating organizational health of social security sistan and baluchestan effective

- Hypothesis 4: organizational alignment to create value organizational health and social security in sistan and baluchestan is effective. 


\section{Methodology}

The research in terms of data collection and the research method is descriptive. From resources libraries, interview with experts and the questionnaire used to gather information is and the purpose of this investigation, interval scale and Likert response to selection the study population will include staff managers of social security in sistan and baluchestan. The research community, including managers and employees in various branches of the province, it has 500 inhabitants. A sample study morgan used to determine the sampling table. The sample size was estimated at 225. That in indeed almost half of the sample to the entire population is. The two questionnaires were taken to include aspects of spirituality and health. An organization consisting of 42 questions (question five option from strongly agree to strongly disagree) is one questionnaire for independent variable (spirituality enterprise) the dependent variable (organizational health) used. Reliability coefficient cronbach's alpha reliability of the questionnaire was used obtained / spirituality and health questionnaire $96 \%$ is. The random questionnaire the sample was collected.

\section{Data Analysis Methods}

In this study, to analyze the data obtained from the sample, statical methods descriptive and inferential statistics were used is. The variables with the help of methods descriptive statistics (to describe the frequency and percentage data) and statical methods inferential (multi-liner and regression analysis) to test hypotheses were used. All calculations are done with SPSS software version 22 is. The impact and the relationship between independent variables and related specified.

\section{Discussion}

This study was conducted to review work on spirituality organizational health and social security in sistan and baluchistan have been implemented.

\subsection{Factor analysis}

In the present study to evaluate the model of analysis confirmatory factor which is used community data is studied.

Table 2: Results of factor analysis

\begin{tabular}{|c|c|c|}
\hline Error level(Sig) & Bartlett test & Kmo test \\
\hline 0,000 & 3996,221416 & 0,937 \\
\hline
\end{tabular}

As in table 2 can be seen, kmo test whose result is equal to 0,937 indicates of is possibility of reducing the number of is infrastructure. In addition, the result Bartlett's test 3996,221416 at the significant level is less than 1\%, which indicates the correlation matrix is not the same, that is, on the one hand between the statements. A high correlation exists within each of the statements of another factor not observed any correlation to determine the correlation matrix between the item and operating and categorize any item in any of the removal of items that values are less than $55 \%$ and remove the variables that distinguish ability in. Not between different platforms, Final factor analysis Table 2 results.

Table 3: final results of the factor analysis

\begin{tabular}{|l|c|c|c|}
\hline Items & \multicolumn{3}{|c|}{ Variables } \\
\hline & $\mathbf{1}$ & $\mathbf{2}$ & $\mathbf{3}$ \\
\hline Meaningful Work1 & 0.778 & & \\
\hline Meaningful Work2 & 0.790 & & \\
\hline Meaningful Work3 & 0.673 & & \\
\hline Meaningful Work4 & 0.480 & & \\
\hline Meaningful Work6 & 0.788 & & \\
\hline Meaningful Work7 & 0.722 & & \\
\hline Solidarity1 & & & 0.799 \\
\hline Solidarity2 & & & 0.731 \\
\hline
\end{tabular}




\begin{tabular}{|l|c|c|c|}
\hline Items & \multicolumn{3}{|c|}{ Variables } \\
\hline & $\mathbf{1}$ & $\mathbf{2}$ & $\mathbf{3}$ \\
\hline Solidarity3 & & & 0.657 \\
\hline Solidarity4 & & & 0.832 \\
\hline Solidarity5 & & & 0.780 \\
\hline Set by organization's Values1 & & & 0.549 \\
\hline Set by organization's Values2 & 0.782 & & \\
\hline Set by organization's Values4 & 0.816 & & \\
\hline Set by organization's Values6 & 0.768 & & \\
\hline Set by organization's Values7 & 0.807 & & \\
\hline
\end{tabular}

The above graph (chart pebbles), results of previous table to the appropriate number of agents to as the picture shows. As the visible graph 3 of the amount Special greater than one, in fact, 23 statements by eliminating waste was items into three categories.

\subsection{Liner regression}

One of the assumptions of regression, the normal distribution variables in the model fit is high. Therefore, in this study, test for normally distributed variables. Kolmogorov-smirnov one-sample used that in table 4 are shown.

Table 4: check the kolmogorow- smirnov test

\begin{tabular}{|l|c|c|}
\hline Items & \multicolumn{2}{|c|}{ kolmogorow- smirnov test } \\
\hline & Statistic & Sig \\
\hline Meaningful Work & 0.116 & 0.000 \\
\hline Solidarity & 0.083 & 0.010 \\
\hline Set by organization's Values & 0.089 & 0.000 \\
\hline Health organization & 0.054 & 0.001 \\
\hline
\end{tabular}

According to table 4, the results of Kolmogorov Simonov shows that the values obtained in less than significant levels $1 \%$ and with respect in the amount of between $+1,96$ and $-1,96$ is the normal distribution of data.

\subsubsection{Alignment tests}

One of the assumptions of regression, multicollinearity is the independent variable, because if some estimates have the linearity of these variables cross and standard errors swing will be great. For this purpose, statistics tolerance and variance inflation factor uses is. A tolerance is a variable proportion of the independent unforeseen variance. The tolerance factor between 0 and 1 has shown that variables how much have independent relationship with each other. The purpose of this study was to test the time is liner.

Table 5: information on the test strip

\begin{tabular}{|l|c|c|}
\hline \multirow{2}{*}{ Items } & \multicolumn{2}{|c|}{ test strip } \\
\cline { 2 - 3 } & VIF & Tolerance \\
\hline Meaningful Work & 1.097 & 0.677 \\
\hline Solidarity & 1.861 & 0.750 \\
\hline Set by organization's Values & 1.513 & 0.685 \\
\hline
\end{tabular}

The above table shows that on average variables studied tolerance in communities up which indicates that, in the line between low is also an indicator variable results the other variance inflation factors in communities. The research community is smaller than the number 2 in other words, data on implementation of regression with high confidence. 


\subsubsection{Multiple linear regressions}

Table 6: information on entry variables regression

\begin{tabular}{|c|c|c|c|}
\hline Model & Input variables & Deleted variables & Method \\
\hline & The meaning of work, feeling of solidarity , convergence of values & 0 & Simultaneous method \\
\hline
\end{tabular}

Table 6, the first output regression test shows that variable to predict changes brsasas three independent variables related organizational health, Enter a regression model and method is used.

Table 7: Information about the summary regression model

\begin{tabular}{|c|c|c|c|c|}
\hline Model & R & R Square & Adjusted R Square & Std. Error of the Estimate \\
\hline 1 & 0.780 & 0.608 & 0.603 & 0.48713 \\
\hline
\end{tabular}

Table 7, Show short model, solidarity coefficient( $R$ ), between variables is 0,780 that show between the independent variables and related research correlation variable there are strong but moderating coefficient of determination is 0,603 that shows 60.3 percent total changes in organizational health, dependent on three independent variables would more than half of the variance in the dependent variables organizational health estimate.

Table 8: Information processing model in regression

\begin{tabular}{|c|c|c|}
\hline Model & Sig & F \\
\hline 1 & 0.000 & 114.882 \\
\hline
\end{tabular}

Due to the significance $F$ Test $(114,882)$ in the less than 1 percent of error level it can be concluded the research consists of 3 independent variable regression model and the dependent variable (organizational health) is good model and independent variables can be set estimate changes in organizational health.

Table 9: details the impact factor regression not standardized and standardized

\begin{tabular}{|l|c|c|c|c|c|}
\hline \multirow{2}{*}{ Model } & \multirow{2}{*}{$\mathrm{Sig}$} & \multirow{2}{*}{} & Standardized Coefficients & \multicolumn{2}{c|}{ Unstandardized Coefficients } \\
\cline { 5 - 6 } & & & $\mathrm{B}$ & Std. Error & Beta \\
\hline Constant & 0.000 & 6.916 & & 0.099 & 0.685 \\
\hline Meaningful Work & 0.494 & 0.534 & 0.032 & 0.060 & 0.032 \\
\hline Solidarity & 0.000 & 5.530 & 0.393 & 0.063 & 0.005 \\
\hline Set by organization's Values & 0.000 & 5.131 & 0.404 & 0.075 & 0.386 \\
\hline
\end{tabular}

In Table 9, the interpretation of the regression coefficients based on the coefficient beta done because the statistics show each of the standardized regression is coefficient of the independent variables on the dependent variable. Due to the error, the amount of $t$, variable feel solidarity and harmony values because the error of the value of $t$, is lower than $5 \%$ have a variable impact on organizational health but due to level variable with mean error higher than 5 percent on the impact of changing organizational health is not desirable. On other hand, the variable alignment regression coefficient values with 0.404 have a highest regressive impact. In the table 10 three correlations can be observed:

Table 10: Information about the correlations rating zero, separate and split half

\begin{tabular}{|l|c|c|c|}
\hline \multirow{2}{*}{ Model } & \multicolumn{3}{|c|}{ Correlation } \\
\cline { 2 - 4 } & Zero-Order & Partial & Part \\
\hline Meaningful Work & 0.571 & 0.036 & 0.022 \\
\hline Solidarity & 0.737 & 0.348 & 0.232 \\
\hline Set by organization's Values & 0.742 & 0.326 & 0.216 \\
\hline
\end{tabular}




\section{Conclusions and Recommendations}

requires each community to have a healthy and dynamic organization health organization so physically, psychological, safety, belonging, merit and value. Investment in knowledge, expertise, and character stakeholders, and growth on its capabilities and perform tasks assigned learn from their systems by part of the system has a considerable impact of the spirituality in workplace is one of the processes, important business and management in the twenty-first century. We must seriously consider the mid-nineties. Gyakalvin(2015), said: create the framework of special value to performance can organization struck under the influence. Results of the analysis of field data through regression and correlation coefficient indicates 0.780 shows between independent variables (meaning work, solidarity, harmony values) and variables related research correlation. So there is a strong organizational health in social security organization of sistan and Baluchistan, so this research the development of other studies conducted in workplace is as follows:

Moghimi (2008) The study showed that between resident and co-workers spirituality and creativity significant relationship there. Nikpour (2011) showed that the components of workplace spirituality and behavior. There is significant organizational citizenship. Rahimi(2014) said: spruce and significant relationship between workplace spirituality and customer satisfaction is there are independently. Gyakalvin(2015) there are between the dimensions of spirituality in the workplace with meaning, sense of solidarity and alignment values and organizational change leadership. Change the organizational climate and organizational learning capital attitudes and work together there.

Gyakalvin(2015) spirituality workplace organizational performance get the appeal of spirituality in the workplace, development of new paradigms in organizational sciences led. Ajla(2013) On the workplace spirituality happiness employees in an industrial environment effectively. Denton (1999) showed between religion and spirituality the distinction was emphasized. Tendency experience many spiritual practices in the workplace respectively. Often the use of words spirituality and religion in the work place were anxious. Like western culture, their spirituality phenomenon individual understood. Dmvras(2003) stated in micro-level of spirituality in workplace can cause social and political participation and a sense of connection with members in the organization .Mylymn et al(2003). their study concluded that spirituality in work place, the causes job attitudes, organizational commitment, job involvement, reduce and . kynjrsky and askryping(2004) investigation showed that spirituality in the workplace, ie distinct from view di have physical dimensions, emotional, cognitive, interpersonal. Spiritual, and in fact, including a sense of connecting with others and collective purpose, a sense of connection with entity premiere and a sense of perfection and excellence is.

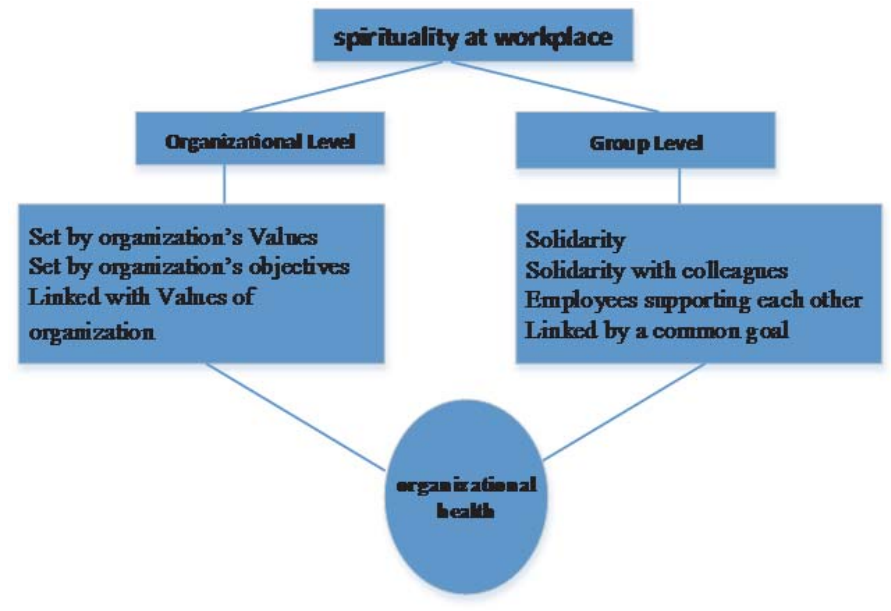

Figure 2: Final conceptual model of research

from the perspective of Kate Davis, when healthy organization those employees feel they are doing something useful and to foster a sense of personal loss find. Their most exciting thing that provides inner happiness, love, you accept. Many of the responsibility and opportunity progress and prosperity of their job search. Employees want to listen to their words data and treat them as if although the value of each individual. They want to ensure that the organization truly compassion for their needs and problems.

The Ligeti(1997) characteristics of organizational health, it mission is to work, the requirement to care, feeling of 
health, communication, leadership, risk to improve the quality, team building, thinking, strategic, strategic planning, structure Environment, spirit and vitality, organizational openness, culture change is quoted the moderator in a division of the organization`s health manager penetration ability to influence superiors manufacturing maintenance task-oriented and success-oriented manager consideration friendly, supportive, open and cooperative supported across the necessary materials, spirit feel confident, confidence and compassions the staff and scientific emphasis insists organization for learning know as Miles, the factors in creating and maintaining organizational health and durability survival of the organization in their workplace and adapt it and upgrade and expand its ability to adapt further considers that the most important factors for creating and health maintenance organizations in PC includes: communication, participation and involvement in the organization, morale, morality, identification or recognition performance, the aim, leader ship, performance improvement or development staff and resources have been used. The indicators focus my capacity. in the years of the aim communication, power parity, draws staff to access and influence the leader or head of the organization taking advantage of the resources to please use the talents of employees, attractions organization, employee morale, innovation, staff capacity in the need to director ,sustainability and the ability to problem-solving health maintenance organization introduced the still by organizational health assessment that diagnosis and organizational health development including shrek host, the most important factors in creating and health maintenance organization used now detects and development commission national service Australian model health maintenance organization provided that it involves coordinating elements, leadership, ability, power, communication and culture thus, according to a study in the organization social security in sistan and Baluchistan was through spirituality can be felt alignment with the values of solidarity and as a creating and maintaining organizational health be taken into account.

The concept of positive organizational health in an organization, growth and developments has facilitated, or cause dynamics of the organization. The ability to adapt the organization with their environment, creating harmony among members organization and achieve organizational goals such as was the use of organizational health benefits. a door total work effectively implies organization the lower cost or speed, in short-term to effectively acts, may damage to morale and employee satisfaction. Measures such as job rotation, job enrichment, due to unsatisfactory job, the feeling of importance and identity and finally get feedback from occupation, perception of meaning in work will improve. Creating an intimate atmosphere and is communion and cooperation among staff. They reduce stress and create intimacy with employees a kind of social capital in the organization and feel solidarity and consensus staff increases. A door if the mission, vision and organizational goals clearly explained to staff and consider feedback from staff is. Comments about the value of the organization's staff term, and the health, welfare and morale and conditions life care workers, and health, welfare, morale and living conditions of staff given, staff and organizational goals and values accepted and will easily follow. The purpose of MBO and target-based model set out clear goals and objectives of the organization and alignment with these goals through society such as that of employees these goals can be met.

\section{Resources}

Abedi Jafari .H. and .Rastegar. A.A. (2007). The emergence of spirituality in organizations, concepts, definitions, assumptions, conceptual model. Journal of Management Science, Issue 5, pp. 121 - 99.

Ajala E.M. (2013)The Impact of Workplace Spirituality and Employees Wellbeing at the Industrial Sector: the Nigerian Experience, 3 Volumes 13, No. 2.Myers 1995.

Hosseini nasab .S. D. Mustafa Poor, K. (2012) The relationship between communication skills and organizational health of Tehran Pars Abad schools in the academic year 2011-2010. Journal of Education, No 19, pp. 40 - 27.

Hannells R. 1995. A new dictionary of religions, (2nd edition) black - well.

Khorasani.A, Mahbobi.M, Etemadi. M,Ghiasi.M. (2012The relationship between spiritual health and social anxiety chemical warfare. Journal of Isfahan University of Medical Sciences, Volume XI, No. IV. 27.

Kennedy MH.(2002). Spirituality in the workplace an empirical study of this phenomenon among adult graduats of a collage degree completion program. Dissertation abstracts international, A 63 (1). 269 (UM No. 3039604).

Gatling A. (2015)A Causal Model for Integrating Workplace Spirituality into Hospitality Organizational Transformation, Journal of Human Resources in Hospitality \& Tourism, On: 11.

Gibbons P. (2001) Spirituality at work: A pre - theoretical overview, MSC. Thesis - birnbeck collage, university of London.

Mohammadi ,Fereshte, Mahmoud Hazrati and Ahmad Jafari. (2013), Examine the relationship between workplace spirituality and perceptions of servant leadership, Journal of Public Management Research, Vol 6, № 20.

Mitroff and Denton. (1999). Study and spirituality in the workplace. Translated by Ali prosper, journal Science, No. 37.

Mayers JE. ( 1990) Wellness throughout the lifespem, guide post, moy. Kavanagh 1999.

Milliman J. Czaplewski AJ. Ferguoson J. 2003. Workplace spirituality and employee work attitudes, journal of organizational change management, Vol 16, № 4, P: 426 - 447.

Moghimi.C.M and Rahbar.A. (2007). organizational spirituality and its impact on employee creativity (comparative approach). Journal of 
Ethics in Science and Technology, Issue 3 and 4, pp. 98 - 89.

Riahi, M.A. Voridi neya.A.M. Pourhossein .Z. (2008) the relationship between social support and mental health. Journal of Social Welfare, Issue 39.

Tahmasebi pour.R. and Babashah .J. (2002) the role of religion and spirituality in globalization. Management Studies, No. 56. 